\title{
CORRESPONDENCE
}

\section{Nuclear technology is not the threat}

SIR,-Mr A. B. Lovins' article (28 February, page 817 ) confines itself almost entirely to a discussion of the use of reactor grade plutonium in the construction of bombs, eithe by terrorist groups, or by governments. I do not believe myself to be enough of an expert on these esoteric branches of industrial chemistry and nuclear physics to comment usefully on the technical aspects of the article, and in any case I would prefer to concentrate on some implicit non-technicalities.

First, there is the claim, not made here by Mr Lovins, that the increased availability of dangerous materials will increase the risk of their misuse. While there is some truth in this depressing doctrine, I feel that the size of such risks is dominated by the proportion of people who are keen to use terrorist methods, rather than by the technology of their particular community.

No, the question surely is whether we are to give up clean, reliable, safe, economical and enormously useful techniques simply for fear of what the malevolant may do. If we are, where does this line of argument stop? Do the Friends of the Earth want us to give up aviation, liquid natural gas, or genetic engineering? And if not, why not? Or, to put it another way, should Adam have stopped Eve from eating that Fruit?

In addition, I have some specific quarrels with Mr Lovins' article. Who, for instance, were the "three high-technology nations" whose ministers were so misled? Again, noone associated with the anti-nuclear movement is entitled to complain about "lost, oversimplified or garbled"' advice. And what on Earth does he mean by saying that "the implication that the effects of even a crude, minimal 0.1-1 kton explosion would be tolerable for a free society is at best disingenous."? Non-free societies are entitled to proceed, apparently.

Without making any statement about the possible carnage in such an explosion, I would like to point out that conventional accidents sometimes take thousands of lives in free societies, and presumably in non-free ones too. The multiple standards of response to such disasters is sadly but glaringly highlighted by the failure of the Morbi dam in Gujrat State, India, in August. It seems to have taken some hundreds of lives at least, and passed almost unnoticed in the Year of Three Mile Island.

Yours faithfully,

J. F. CRAwFord

Klein Doettingen,

Switzerland.

\section{Comparing the diets of laboratory animals}

SIR, - It has been demonstrated several times that toxicological experiments performed in different laboratories are liable to unexplained variations in result. Amongst the possible reasons for this observation, are differences in diet of the experimental animals (see for example Hathcock and Coon Nutrition and Drug Interrelations, Academic Press, New York 1978). Of 89 randomlychosen recent publications in the fields of oncology, pharmacology and toxicology, more than half failed to specify the diet fed to their laboratory rodents. Often considerable portions of the 'methods' section were description of the animals, sources of chemicals used, etc, but the nearest any of the authors got to specifying their diets was to give the manufacturer's name. This implies that the authors consider stock diets to be standard. However, my survey of $24 \mathrm{UK}$ stock diets for mice and rats has shown that for each nutrient, very large differences in the diet composition exist. Amongst nine minerals, the coefficient of variation ranged from $16 \%$ to $80 \%$, with a median value of $28 \%$. Similarly for 12 vitamins, the range was from $20 \%$ to $91 \%$, with a median of $62 \%$.

The survey was based on the best information available, but in all cases it is a calculated figure only, based on the ingredients of the diets. Only one British manufacturer has been prepared to supply details for one diet of average analyses after production. Some manufacturers at extra cost will provide analytical details to customers on a batch basis, and it is these figures that are required for a scientific evaluation of diets on a comparative basis. The majority of nutritionists use semi-synthetic diets, rather than stock diets, and it is perhaps for this reason that their attention has not been focused on diets used by non-nutritionists and why so little nutritional work has been done in this field.

It is the intention of the Laboratory Animals Centre to try to obtain information about actual analyses, for nutrients and contaminants, on stock diets worldwide. It would then be possible to help those who are trying to explain differences in results between similar experiments in different laboratories, in which it is suspected that dietary variation might have been important. In the furtherence of this aim, it is suggested that diet manufacturers and scientists who have relevant analytical data should contact the Laboratory Animals Centre to discuss the possibility of collaboration in such a study.

\section{Yours faithfully,}

Medical Research Council

Laboratory Animals Centre

Carshalton, Surrey, UK

\section{Establishing the case for the Maunder Minimum}

SIR,-The News and Views contribution of 31 January (page 427) entitled "Was there a Maunder Minimum?" projects a superficial understanding of the meticulous work by solar astronomers, historians, climatologists,

palaeobiologists, and scientists from a host of other research disciplines supporting a marked diminution in solar activity during the 17 th century.

Table 1 of the article shows that there were nine naked eye sunspot records during the decade beginning 1610 , six in the $1620 \mathrm{~s}$, nine in 1639 , two in the $1640 \mathrm{~s}$, three in the $1650 \mathrm{~s}$, one in the subsequent decade, then none, and finally one in the $1680 \mathrm{~s}$. Taken at face value, the new fang chih records would seem to lend support to a dramatic reduction from about 1640 in the number of sunspot groups or individual spots large enough to be seen by the naked eye under suitable atmospheric conditions. But a direct interpretation of such limited data is superficial. As your article stresses, the fang chih do not present an unbiased sample of data, any more so than the records in the official dynastic histories. At least for the latter one has some check on completeness of the data by looking at the continuity of official records of other astronomical phenomena. However, because of political, social and astrological influences, oriental sunspot records are by themselves of little value; as previous investigators have been careful to stress, they provide at best merely circumstantial evidence for excursions in solar activity. There is no point arguing for or against a Maunder Minimum on the appearance or absence of naked-eye sunspot records from the orient when post-telescopic (1610) occidental records, free from politicalastrological influences, are available and when a wealth of other indicators of solar variability have been investigated. Yet none of these are mentioned, the reality of the Maunder

Minimum being called into question on the basis of a few provincial oriental records of doubtful reliability.

The leading late 17 th century observational astronomers lamented the scarcity of sunspot activity. Here we have more than just a chance mention of detections, but professional observers insisting that it had been a decade or more since any spots had been seen. Spots there certainly were during the Maunder Minimum (1645-1715) but greatly reduced in frequency and extent. Thus, for example, Stephen Gray noted in 1705 "the Sun was much more productive of (spots) in (Galileo's) time than it has yet been in ours, and the Regions Producing them had a far Greater extent"'. However, if one was hesistant to accept the direct evidence of contemporary scientific writings, indirect indicators provide near-conclusive proof of reduced solar activity. A history of the flux of cosmic rays, related to solar activity (and thence to sunspot occurrence) can be constructed from isotopic anomalies preserved in tree rings and ice cores. All such investigations reinforce the case for the Maunder Minimum.

Yours faithfully,

David Clark

Royal Greenwich Observatory, Hailsham, Sussex, UK

F. R. STEPHENSON

University of Liverpool

For any readers wishing to follow up the original Chinese language paper on which the News and Views article was based the reference is Nanjing Daxue Xuebao (Ziran Kexue Ban No. 2/31/1979 and not 1976 as printed: ED

\section{Lead petrol additives}

SIR,-In an otherwise valuable contribution to the debate on the health impacts of childhood lead exposure, M.R. Moore (24 January, page 334) may have unnecessarily compromised the case against leaded petrol by conceding significant economic benefits.

It has long been accepted that lead petrol additives are a major contributor to

combustion chamber deposits responsible for increased octane rating demand.

Measurements of this effect (e.g. G. Cornetti et al, The Journal of Automotive Engineering, June $1971,8-14$ ) have demonstrated fuel efficiency penalties that are greater than the gains made possible by increased compression ratios with high octane, leaded petrol.

\section{Yours faithfully,}

David R. L. Davies

Centre for Resource ana Environmental Studies,

Australian National University, Canberra 